\section{Electronic cigarettes: peering through the smokescreen}

\author{
Martin McKee
}

Health professionals and their patients have every reason to feel confused. One week the WHO issues a position paper calling for strict regulations on electronic nicotine delivery systems (ENDS), more commonly referred to as electronic cigarettes, including restrictions on marketing and a ban on using them in enclosed public spaces. ${ }^{1}$ The next week, a group of scientists attracts widespread media attention, with headlines claiming that these products could save 50000 lives in the $\mathrm{UK},{ }^{2}$ although this figure appears nowhere in the corresponding paper. ${ }^{3}$ What is one to make of these conflicting messages?

Before reviewing the evidence, some context is necessary. For several decades the tobacco industry, which has been rapidly increasing its share of the market for ENDS sold in the UK, ${ }^{4}$ has actively sought to create confusion. It did this very successfully when it sought to block bans on smoking in public places, engaging in a massive campaign of deception. ${ }^{5}$ It sought to portray second-hand smoke as harmless, even though its own research showed that sidestream smoke was even more toxic than directly inhaled smoke. ${ }^{6}$ It also promoted the idea that a ban would hit the takings of bars and restaurants, even though it had funded the only research to show such an effect. ${ }^{7}$ As one of its leading scientists claimed, in discussions with lawyers advising on the tobacco industry's strategy, 'he could bring a healthy scepticism to ... some of the claims being made about environmental tobacco smoke'. ${ }^{6}$ The industry has also been very good at displacing attention from more important issues, and it is noteworthy that, since the apparent controversy about ENDS has erupted, there has been virtually no media coverage of the UK government's failure to take forward its commitment on standardised packaging, another area where industry funded research has been used to create a misleading appearance of uncertainty. ${ }^{8}$ Hence, in an area that is potentially so important to the large tobacco

Correspondence to Professor Martin McKee, European Centre on Health of Societies in Transition, London School of Hygiene and Tropical Medicine, London WC1H 9SH, UK;

martin.mckee@lshtm.ac.uk manufacturers, an impression of academic doubt and uncertainty is to be expected.

So where should health professionals look to help their patients reach a decision about ENDS? There is no shortage of advice. The manufacturers of these products have established a massive online presence, many apparently from individual users (self-styled as 'vapers') whose enthusiasm for these products is such that they seem to spend many hours each day blogging and tweeting their benefits free from the constraints that would be imposed if they were producing official advertisements. More worryingly, they also engage in grossly offensive online attacks on anyone who has the temerity to suggest that ENDS are anything other than an innovation that can save thousands of lives with no risks, ${ }^{9}$ with at least one of the most active individuals affiliated to an organisation known to receive tobacco industry funding. ${ }^{10}$ Interestingly, despite attacking critics of ENDS for seeking to prevent use of what they see as life-saving devices, some of these bloggers are equally critical of measures such as standardised packaging, that really would reduce tobacco induced harm. There are also a few health professionals, largely drawn from the field of nicotine addiction (along with some whose background is in harm reduction among intravenous drug users who see an analogy), who do consider that they may help the particular group of patients they work with and who have been especially vocal in eliciting support for ENDS.

In marked contrast, patients and health professionals can seek advice from any of a number of leading national and global health organisations (box 1) that take a quite different view. Each has undertaken detailed reviews of the available evidence, and while noting that there are still many gaps, reflecting the novelty of these products, the lack of data on the long term effects of deeply inhaling the many flavouring additives and by-products of the heating system, such as a range of metals, and natural suspicions about the rapidly growing presence of the tobacco industry in this market. There is a high level of consensus among these organisations, supported by the systematic review undertaken for the WHO. ${ }^{11}$ Based on their assessments, it is possible to offer some answers to questions that might be asked by those contemplating using ENDS.

\section{IF I USE ENDS, WILL I REDUCE MY RISK OF GETTING SMOKING-RELATED DISEASES?}

Self-evidently, any health effects of using ENDS will be different from those of smoking as the composition of what is inhaled is different. ENDS do not contain the tar that is the main cause of lung cancer. However, although the advocates of ENDS argue that nicotine is 'as safe as caffeine', it is now clear that this is not the case. Its effects may have been obscured by being mixed with tar in cigarettes, but there is growing evidence that it interferes with cellular messaging in ways that are likely to promote cancer development in normal cells ${ }^{12}$ and promote tumour growth and spread of existing cancers. ${ }^{13}$ ENDS users achieve similar levels of serum cotinine, a marker of nicotine absorption, as is seen with traditional cigarettes. ${ }^{14}$ While this is an area where more research is needed, as recognised by the International Agency for Research on Cancer, which has prioritised research on its effects, ${ }^{15}$ the precautionary principle would suggest that the advice that pregnant women and breastfeeding mothers should stop smoking should also cover ENDS. ${ }^{16}$

Further concerns relate to the other substances produced by ENDS. Although advocates commonly state that this is only water vapour, this is not the case. ENDS produce levels of ultrafine particles that are similar to those with traditional cigarettes ${ }^{17}$ and these are associated with release of nitric oxide, suggesting a potential hazard to those at risk of cardiovascular disease. ${ }^{18}$

There are also concerns about levels of cytotoxic metals in e-cigarette vapour, produced by heating elements, ${ }^{19}$ certain flavourings, such as diacetyl, known to cause lung serious disease, ${ }^{20}$ and a range of other chemicals. Advocates of ENDS respond that many of these are present in low levels, but ignore how some users may be inhaling these deep into their lungs for decades and, just because something is considered safe as a food additive, this does not mean that it is safe when inhaled over such a period.

\section{WILL ENDS HELP ME TO QUIT SMOKING?}

Although there is a wealth of anecdotes from the advocates of ENDS, the single randomised controlled trial found that ENDS were not significantly better than standard nicotine replacement therapy (NRT). ${ }^{21}$ This was despite this trial placing barriers in the path of those randomised to 
Forum of International Respiratory Societies

'... electronic nicotine delivery devices should be restricted or banned until more information about their safety is available. If they are allowed, they should be closely regulated as medicines or tobacco products. ${ }^{33}$

\section{International Union against Tuberculosis and Lung Disease}

'The safety of electronic cigarettes (ECs) or electronic nicotine delivery systems (ENDS) has not been scientifically demonstrated. Adverse health effects for third parties exposed (second-hand exposure) cannot be excluded because the use of electronic cigarettes leads to emission of fine and ultrafine inhalable liquid particles, nicotine and cancer-causing substances into indoor air. The benefits of e-cigarettes have not been scientifically proven. ... ENDS could undermine the implementation of the WHO Framework Convention on Tobacco Control.' 34

\section{American Heart Association}

'There are concerns that e-cigarette use and acceptance of e-cigarettes has the potential to renormalise smoking behaviour, sustain dual use, and initiate or maintain nicotine addiction. Their use also could serve as a gateway to reinitiation of smoking by ex-smokers. Unregulated e-cigarette use also has the potential to erode gains in smoking cessation and smoke-free laws. The AHA [American Heart Association] considers e-cigarettes that contain nicotine to be tobacco products and therefore supports their regulation under existing laws relating to the use and marketing of tobacco products. ${ }^{35}$

\section{UK Faculty of Public Health}

'What we really need is for electronic cigarettes to be subject to the same controls as tobacco, and e-cigarettes to be treated as a tobacco product, so they cannot be marketed or advertised. ${ }^{36}$

\section{British Medical Association}

'It is encouraging that the WHO shares our concerns surrounding e-cigarettes and has joined us in calling for stronger regulation.... Tighter controls are needed to ensure their use does not undermine current tobacco control measures and reinforces [sic] the normalcy of smoking behaviour.' ${ }^{37}$

NRT, who were required to take a voucher to a pharmacy to obtain it. Given the absence of robust experimental evidence, advocates of ENDS selectively cite observational studies, ignoring those that challenge their arguments. An example is the analogy with smokeless tobacco, or snus, legally sold in Sweden, with frequent use of a graph showing a decline in smoking coinciding with increased use of snus. Yet, disaggregation by sex shows similar changes in smoking by men and women although snus use is extremely rare among women. ${ }^{22}$ Another widely cited example uses observational data from England, arguing that the chances of success among those intending to quit are twice as high among those using e-cigarettes compared to those using NRT. Yet, these data show that $80 \%$ of those attempting to quit with ENDS in the preceding year were still smoking, hardly a miracle solution, and inexplicably the success rate among those using NRT was lower than among those whose attempts were unassisted. ${ }^{23}$ There is also a risk that the use of ENDS may reduce the intention to quit completely. In summary, therefore, this is an area where robust evidence of effectiveness is missing.

\section{WILL I IMPROVE MY HEALTH CHANCES IF I USE ENDS TO HELP ME CUT DOWN ON CIGARETTES?}

The risks associated with smoking are nonlinear, which is unsurprising given the many toxic substances in tobacco smoke and the diverse organs that they act upon. However, there is now good evidence from a number of cohort studies showing that those cutting their cigarette consumption by more than half obtain few health benefits. $^{24-26}$ The only benefit is a reduction in lung cancer, but even that was smaller than expected. Hence, the evidence is clear. To achieve health benefits it is necessary to quit, not cut down.

\section{SHOULD I TAKE ANY PRECAUTIONS WITH ENDS AND THEIR CONTENTS?}

Nicotine is a potent poison. ${ }^{27}$ Yet the introduction of ENDS means that concentrated solutions are now being packaged in colourful containers and mixed with flavours that seem designed to appeal to children, such as 'Gummy Bears' and bubble gum. In these circumstances, it is unsurprising that there are increasing instances of poisoning of those ingesting the contents of containers. ${ }^{28}$ Hence, it is important that ENDS be stored safely, where children and pets are unable to access them.

\section{DISCUSSION}

These questions are likely to be the ones most commonly asked of health professionals. However, in their role as advocates for health, it is important that they also take account of the wider context. ENDS manufacturers, now dominated by the major tobacco companies, engage in intensive marketing that seems to be targeted at young people. Thus, a group of US senators has described their sponsorship of sports events and use of flavours and images of celebrities that appeal to young people, ${ }^{29}$ with their concerns borne out by studies from the USA ${ }^{30}$ and UK. ${ }^{31}$ A further concern is the manufacture of what are termed electronic shishas, which contain flavours but no nicotine and so, in many countries, can be sold to children, thereby getting them into the habit of using the same equipment as with ENDS. This marketing also seems to be designed to circumvent advertising bans, for example by the promotion of products looking like cigarettes and packaged in ways that look like established brands. There are also concerns that the use of products that resemble cigarettes (so-called cigalikes) will renormalise the imagery of smoking that has been so effective in movies, where cumulative exposure to scenes of smoking are strongly correlated with youth smoking. ${ }^{32}$ Finally, it is clear that the tobacco industry, by presenting itself as part of the solution to smoking related illness, is using ENDS to return to the days before the Framework Convention on Tobacco Control when it still had open access to governments.

From a public health perspective, any innovation should prompt three questions. Is it safe, does it work, and who 
benefits from its introduction? There are still very large gaps in the evidence but, on the basis of what is known, the answers are that ENDS may be safer than traditional cigarettes but there are many reasons for concern about their safety, especially if they are to be used over many years. They may help some people to quit, but do not seem to be any better than NRT and neither are particularly effective. And the beneficiaries are clearly the tobacco companies, who have shown once again their ability to sow confusion in the eyes of the public and now see a prospect of reinventing themselves as legitimate businesses with whom politicians are no longer ashamed to be seen in public.

Competing interests None.

Provenance and peer review Commissioned; internally peer reviewed.

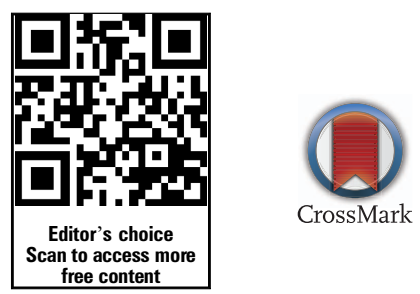

To cite McKee M. Postgrad Med J 2014;90:607-609.

Received 15 September 2014

Accepted 24 September 2014

Published Online First 7 October 2014

Postgrad Med J 2014;90:607-609.

doi:10.1136/postgradmedj-2014-133029

\section{REFERENCES}

1 Backgrounder on WHO report on regulation of e-cigarettes and similar products. Geneva: World Health Organization (WHO), 26 Aug 2014. http:// www.who.int/nmh/events/2014/backgrounder-ecigarettes/en/

2 Bosely S. E-cigarettes could save over 50,000 lives in the UK, experts say. The Guardian, 5 Sep 2014. http://www.theguardian.com/society/2014/sep/05/ e-cigarettes-could-save-50000-lives-in-uk

3 McNeill A, Etter JF, Farsalinos K, et al. A critique of a WHO-commissioned report and associated article on electronic cigarettes. Addiction. Published Online First: 5 Sep 2014. doi:10.1111/add.12730

4 E-cigarettes. TobaccoTactics, 4 Sep 2014. http:/l www.tobaccotactics.org/index.php/E-cigarettes

5 Muggli ME, Forster JL, Hurt RD, et al. The smoke you don't see: uncovering tobacco industry scientific strategies aimed against environmental tobacco smoke policies. Am J Public Health 2001;91: 1419-23.

6 Diethelm PA, Rielle JC, McKee M. The whole truth and nothing but the truth? The research that Philip Morris did not want you to see. Lancet 2005;366: 86-92.

7 Scollo M, Lal A, Hyland A, et al. Review of the quality of studies on the economic effects of smoke-free policies on the hospitality industry. Tob Control 2003;12:13-20.

8 Diethelm P, McKee M. Tobacco industry-funded research on standardised packaging: there are none so blind as those who will not see! Tob Control Published Online First: 7 Jul 2014. doi:10.1136/ tobaccocontrol-2014-051734

9 Mills D. Opponents of e-cigarettes bombarded with abusive 'four-letter emails starting with $C$ and $F$ ' in bitter row with online cult groups. Mail Online, 12 Jun 2014. http://www.dailymail.co.uk/news/ article-2656160/Health-campaigners-receivingincredibly-abusive-emails-bitter-row-alternativesmoking.html

10 Doward J. Health groups dismayed by news 'big tobacco' funded rightwing thinktanks. The Guardian, 1 Jun 2013. http://www.theguardian.com/society/ 2013/jun/01/thinktanks-big-tobacco-funds-smoking

11 Grana R, Benowitz N, Glantz SA. E-cigarettes: a scientific review. Circulation 2014;129: 1972-86.

12 Bavarva JH, Tae H, Settlage RE, et al. Characterizing the genetic basis for nicotine induced cancer development: a transcriptome sequencing study. PLOS ONE 2013;8:e67252.

13 Schaal C, Chellappan SP. Nicotine-mediated cell proliferation and tumor progression in smokingrelated cancers. Mol Cancer Res 2014;12:14-23.

14 Flouris AD, Chorti MS, Poulianiti KP, et al. Acute impact of active and passive electronic cigarette smoking on serum cotinine and lung function. Inhal Toxicol 2013;25:91-101.

15 Straif K, Loomis D, Guyton K, et al. Future priorities for the IARC Monographs. Lancet Oncol 2014; 15:683-4.

16 Questions and answers on electronic cigarettes (ecigarettes) or electronic nicotine delivery systems (ENDS). Geneva: World Health Organization (WHO), Jul 2013. http://www.ctri.wisc.edu/Smokers/ecigs/ who.pdf

17 Zhang Y, Sumner W, Chen DR. In vitro particle size distributions in electronic and conventional cigarette aerosols suggest comparable deposition patterns. Nicotine Tob Res 2013:15:501-8.

18 Schober W, Szendrei K, Matzen W, et al. Use of electronic cigarettes (e-cigarettes) impairs indoor air quality and increases FeNO levels of e-cigarette consumers. Int J Hyg Environ Health 2014;217:628-37.

19 Williams M, Villarreal A, Bozhilov K, et al. Metal and silicate particles including nanoparticles are present in electronic cigarette cartomizer fluid and aerosol. PLOS ONE 2013;8:e57987.

20 E-cigarette liquid bought on Tyneside 'potentially harmful'. BBC News, 31 Aug 2014. http://www.bbc. co.uk/news/uk-england-tyne-28955590
21 Bullen C, Howe C, Laugesen M, et al. Electronic cigarettes for smoking cessation: a randomised controlled trial. Lancet 2013:382:1629-37.

22 Galanti MR, Allebeck P, Magnusson C, et al. Use of snus and lung cancer mortality: unwarranted claim of causal association. Scand J Public Health 2010;38: 332-3.

23 Brown J, Beard E, Kotz D, et al. Real-world effectiveness of e-cigarettes when used to aid smoking cessation: a cross-sectional population study. Addiction 2014;109:1531-40.

24 Pisinger C, Godtfredsen NS. Is there a health benefit of reduced tobacco consumption? A systematic review. Nicotine Tob Res 2007:9:631-46.

25 Song YM, Sung J, Cho HJ. Reduction and cessation of cigarette smoking and risk of cancer: a cohort study of Korean men. J Clin Oncol 2008;26: 5101-6.

26 Hart C, Gruer L, Bauld L. Does smoking reduction in midlife reduce mortality risk? Results of 2 long-term prospective cohort studies of men and women in Scotland. Am J Epidemiol 2013;178:770-9.

27 Diethelm P, McKee M. Nicotine: not just an unregulated poison but now a potential chemical weapon. Eur J Public Health 2011;21:681.

28 Chatham-Stephens K, Law R, Taylor E, et al. Notes from the field: calls to poison centers for exposures to electronic cigarettes - United States, September 2010-February 2014. MMWR Morb Mortal Wkly Rep 2014;63:292-3.

29 Gateway to addiction: a survey of popular electronic manufacturers and targeted marketing to youth. Washington, DC: US Senate, 14 Apr 2014.

30 Grana RA, Ling PM. "Smoking revolution": a content analysis of electronic cigarette retail websites. $\mathrm{Am} J$ Prev Med 2014;46:395-403.

31 de Andrade M, Hastings G, Angus K. Promotion of electronic cigarettes: tobacco marketing reinvented? BMJ 2013:347:f7473.

32 Song AV, Ling PM, Neilands TB, et al. Smoking in movies and increased smoking among young adults. Am J Prev Med 2007;33:396-403.

33 Schraufnagel DE, Blasi F, Drummond MB, et al. Electronic cigarettes: a position statement of the forum of international respiratory societies. Am J Respir Crit Care Med 2014;190:611-18.

34 Bam TS, Bellew W, Berezhnova I, et al. Position statement on electronic cigarettes or electronic nicotine delivery systems. Int J Tuberc Lung Dis 2014;18:5-7.

35 Bhatnagar A, Whitsel LP, Ribisl KM, et al. Electronic cigarettes: a policy statement from the American Heart Association. Circulation Published Online First: 24 Aug 2014. doi:0.1161/CIR.0000000000000107

36 E-cigarettes need same controls as tobacco. London: Faculty of Public Health, 29 May 2014. http://www. fph.org.uk/e-cigarettes_need_same_controls_as_ tobacco

37 BMA response to the WHO report into e-cigarettes. London: British Medical Association, 27 Aug 2014. http://web2.bma.org.uk/pressrel.nsf/wall/ 258CF3FDC71A2A6480 257D410033523D?OpenDocument 